\title{
A Conceptual Design of LoRa based Weather Monitoring System for Smart Farming
}

\author{
Hakk1 Soy $^{1 *}$, Yusuf Dilay ${ }^{2}$ \\ 1* Necmettin Erbakan University, Faculty of Engineering, Departmant of Electrical and Electronics Engineering, Konya, Turkey, (ORCID: 0000-0003-3938-0381), \\ hakkisoy@erbakan.edu.tr \\ ${ }^{2}$ Karamanoglu Mehmetbey University, Vocational School of Technical Sciences, Karaman, Turkey, (ORCID: 0000-0002-5365-5137), \\ ydilay@kmu.edu.tr
}

(1st International Conference on Applied Engineering and Natural Sciences ICAENS 2021, November 1-3, 2021)

(DOI: 10.31590/ejosat.1011947)

ATIF/REFERENCE: Soy, H. \& Dilay, Y. (2021). A Conceptual Design of LoRa based Weather Monitoring System for Smart Farm Management. European Journal of Science and Technology, (28), 906-910.

\begin{abstract}
Internet of Things (IoT) based smart farming applications opens up new opportunities for monitoring the agricultural fields. There are different communication protocols can be used in practice to connect the IoT-enabled devices. Among them, the low-power, wide area network (LPWAN) based protocols are well suited to the specific needs of agricultural applications due to their energy-efficient transmission of small data packets over long distances. This study presents the conceptual design of LoRa based weather monitoring system that can be used to warn the farmers about possible crop damages due to harsh weather conditions. The hardware design of a low-cost weather station has been explained in details. Also, the estimated coverage area of the application to be carried out in order to reduce the risk of apple flowering frost damage risk in Karaman Province, Turkey was evaluated using the Xirio Online radio planning tool. The obtained results have verified the feasibility of proposed weather monitoring system.
\end{abstract}

Keywords: LoRa, Smart Farming, Weather Station, IoT, Xirio.

\section{Akıllı Tarım için LoRa tabanlı Meteorolojik İzleme Sisteminin Kavramsal Tasarımı}

$\ddot{\mathbf{O z}}$

Nesnelerin İnterneti (IoT) tabanlı akıllı tarım uygulamaları, tarımsal alanları izlemek için yeni fırsatlar sunuyor. IoT özellikli cihazları bağlamak için pratikte kullanılabilecek farklı haberleşme protokolleri vardır. Bunlar arasında düşük güç geniş alan ağı (LPWAN) tabanlı protokoller, küçük veri paketlerinin uzun mesafelerde enerji verimli iletimi nedeniyle tarımsal uygulamaların özel ihtiyaçlarına çok uygundur. Bu çalışma, çiftçileri sert hava koşullarından kaynaklı olası mahsul hasarları konusunda uyarmak için kullanılabilecek LoRa tabanlı meteorolojik izleme sisteminin kavramsal tasarımını sunmaktadır. Bu kapsamda düşük maliyetli bir meteoroloji istasyonunun donanım tasarımı detaylı olarak anlatılmıştır. Ayrıca Karaman ilinde elma çiçeklenme don hasarı riskini azaltmak için gerçekleştirilecek uygulamanın tahmini kapsama alanı Xirio Online radyo planlama aracı kullanılarak değerlendirilmiştir. Elde edilen sonuçlar, önerilen meteorolojik izleme sisteminin uygulanabilirliğini doğrulamıştır.

Anahtar Kelimeler: LoRa, Akıllı Tarım, Meteoroloji İstasyonu, Nesnelerin İnterneti, Xirio.

\footnotetext{
* Corresponding Author: hakkisoy@erbakan.edu.tr
} 


\section{Introduction}

Agriculture is one of the most fundamental human occupation and it has a great importance for socioeconomic development of nations. Today, the need for efficiency in agricultural production has become inevitable the due to the increasing world population and the resulting excessive consumption (FAO, 2011). Smart farming is a new vision that adopts the information and communication technologies (ICTs) to increase the quality and quantity of harvests while reducing the cost and environmental impact. It also simplify the farming processes by strengthening the implementation of precision agriculture practices (FAO, 2017; Rubio and Más, 2020).

Precision agriculture mainly depends on the collection, storage and analysis of data for application of the right amount of input (e.g., fertilizers, irrigation water, pesticides and seeds) in the right time and right place (Lohchab et al., 2018; Gyarmati and Mizik, 2020; Andrew et al., 2020). The major motivation is the application of modern methods to effectively monitoring and control of spatial and temporal dynamics associated with all aspects of agricultural production. Thanks to the high-resolution sensor data streams and advanced data analytics, it is possible to get the insight into the within-field variability of soil and weather properties, which are related to crop growth and yield ( $\mathrm{Li}$ and Niu, 2020; Lakhiar et al., 2018).

During the last decade, many farmers have faced some challenges in management of agricultural operations, as they try to produce high yields and protect the environment. Smart farming has a power to overcome the emerging difficulties by integrating artificial intelligence (AI), Internet of Things (IoT), big data and cloud computing technologies with farmers' agricultural activities (Charania and Li, 2020). Especially, the use of IoT-based applications is a key for sustainable crop production in large agricultural fields. Indeed, the IoT is the network of physical devices (also known as things) equipped with sensors, actuators and embedded software (Miorandi et al., 2012). It enables to establish an ecosystem of distributed services that are running on the cloud (Elijah et al., 2018).

The weather plays an extremely important role in agricultural activities of farmers in reaping healthy and abundant yields. Since every stage of agricultural activities depends on the weather conditions, the meterorology is essential for agricultural business. By monitoring the weather parameters (i.e., air temperature, relative humidity, barometric pressure, light intensity, rain, speed and direction of wind) in agricultural fields, the farmers can take precautions ahead of time, during all the stages of growth right from seedling to harvesting (Vining, 1990). Each type of crop requires a specific growing temperature. Besides, some chemicals should be sprayed on dry surfaces, while the others require moisture to trigger the curing reaction. Unexpected rainfalls significantly disturb the crops in harvesting season. Beyond that, the sudden temperature drops pose an immense risk to crop damage due to the frost (Hatfield and Prueger, 2015; EOS, 2021; EPA, 2021).

This study introduces an IoT-based remote monitoring system that aims to provide a reliable agricultural management through real-time weather reports. Here, a number of low-cost weather stations are placed over the large agricultural fields to save the costs and minimize the risks. LoRa connectivity has been used to network distributed weather stations. We have presented the hardware design details of weather station. Also, we have investigated the coverage area of typical LoRa network by considering the flowering frost damage risk of apple orchards in Karaman Province, Turkey.

\section{System Model}

Proposed system consists of a number of low-cost weather stations that are deployed in different geographical locations within a large agricultural field to collectively monitor the meteorological conditions. Figure 1 shows the system model of the LoRa based weather monitoring application. In accordance with LoRa network architecture, each weather station acts as an end device and sends collected data to network server through gateway. LoRaWAN specification allows that more than one gateways, which can receive a message sent by any end device. The gateways collect the data packets from end devices and then forward them to the network server through IP connection.

\section{Hardware Design}

The main contribution of this study is a LoRa based weather station that best suits to requirements of agricultural applications. Figure 2 and Figure 3 show respectively the 3D viewpoints of our designed LoRa weather station from the front and back sides. In our hardware design of weather station, we have used the TE Connectivity's MS8607 series digital sensor that combine three environmental measurements, namely pressure, relative humidity and temperature. The manufacturer have specified the operating ranges of MS8607 sensor as 10 to 2000 mbar, 0 to $100 \% \mathrm{RH}$ and -40 to $85^{\circ} \mathrm{C}$. MS8607 sensor provides all these weather-related parameters recorded as 16-bit values and it sends to microcontroller via I2C interface. It should be emphasized that the MS8607 sensor is very suitable for weather stations due to the ultra-low power consumption as well as high accuracy and compactness (QFN package $5 \times 3 \times 1 \mathrm{~mm} 3$ ) (TE, 2017).

Besides, designed weather station was also equipped with Microchip RN2483 LoRa transceiver module for networking with cloud server. RN2483 module contains a PIC18LF46K22 microcontroller with Semtech SX1276 transceiver. It can be set to serve as an end device in the LoRa network infrastructure with LoRaWAN Class A protocol stack. RN2483 could use both 433 $\mathrm{MHz}$ and $868 \mathrm{MHz}$ license-free Industry Scientific and Medical (ISM) frequency bands. The receiver sensitivity is down to -146 $\mathrm{dBm}$ and the transmitter produces output power adjustable up to $+14 \mathrm{dBm}$. According that, the coverage range is about 5 to $15 \mathrm{~km}$ in urban and suburban areas, respectively (Microchip, 2021).

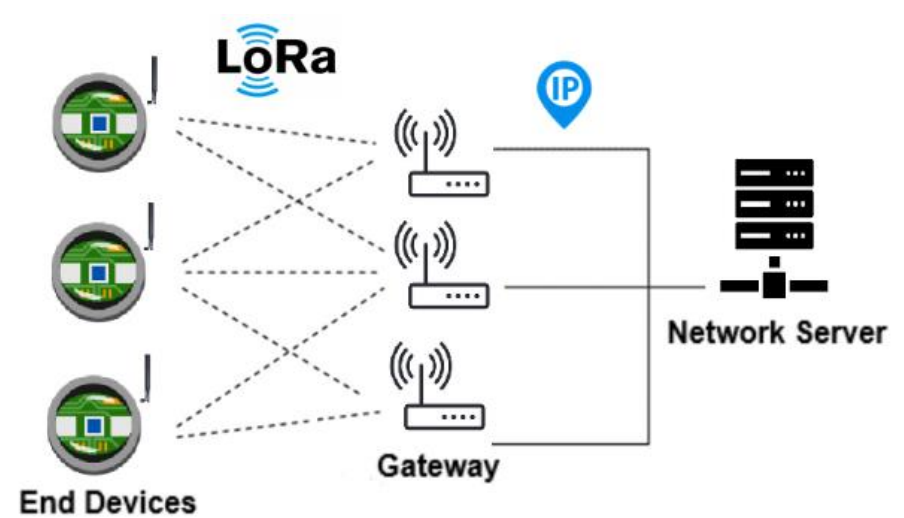

Figure 1. System model of the agricultural weather monitoring 


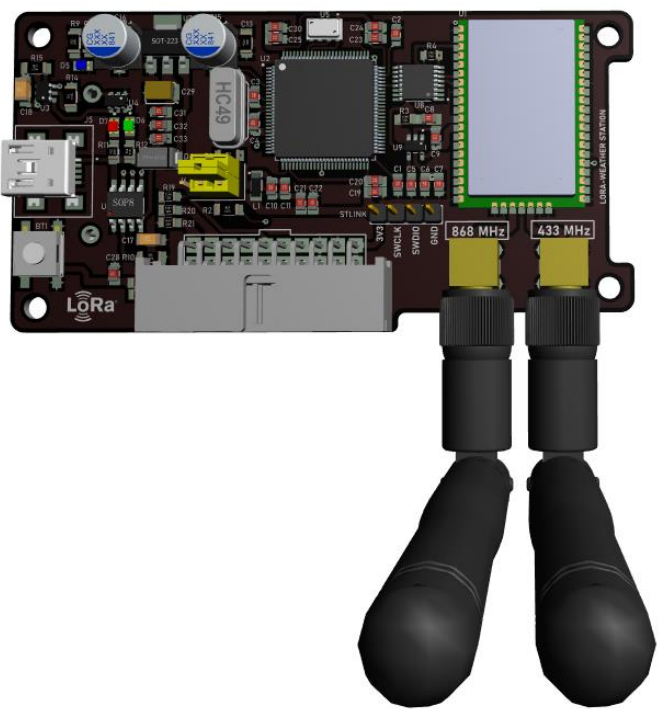

Figure 2. The front side view of designed LoRa weather station

On the other hand, proposed system needs a gateway to complete the signal path from sensors to server. Due to the complexity of both hardware design and especially embedded firmware development procedures, we have preferred to use a ready-made LoRa gateway, namely RAK831 concentrator module and Raspberry Pi single board computer, instead of designing it ourselves. The RAK831 is a multi-channel transceiver module (RAK, 2021), which is designed to receive several LoRa packets simultaneously using different spreading factors on multiple channels. But, the RAK831 needs a host like as Raspberry Pi for management of data streams come from end devices. The host processor of Raspberry Pi can be connected to RAK831 concentrator via USB or SPI lines. Figure 4 shows the RAK831 based LoRa gateway.

In a typical LoRa network, each end device changes the spreading factor (from SF7 to SF12) according to current wireless channel conditions to minimize the bit error rate (BER) of packet transmission, while increasing the data rate. The RAK831 is equipped with Semtech's SX1301 multi-channel modem which is a digital baseband chip including a powerful digital signal processing capabilities. It has a receiver sensitivity of $-142.5 \mathrm{dBm}$ with SX1257 RF front-end transceiver. The SX1301 digital baseband chip contains up to 10 programmable parallel demodulation paths. These are IF0 to IF7 LoRa channels (125 kHz), IF8 LoRa channel $(125,250$ or $500 \mathrm{kHz})$ and IF9 (G)FSK channel (Semtech, 2017). Over the SX1257 connected IF8 channel, SX1301 modem can be established a demodulation path, which is compatible with the signals transmitted by end devices equipped with SX1272 and SX1276 transceivers. Essentially, we have considered to use this connection in proposed agricultural weather monitoring application.

\section{Coverage Analysis}

The other aim of this study is to investigate the coverage area and signal level analysis of the LoRa network, which will be created with reference to designed weather station and gateway. Hereby, we have focus on the apple orchards established in Karaman to minimize the flowering frost damage risk. For this purpose, we have used the Xirio Online radio planning tool from Aptica (Xirio, 2021). The coverage analysis has been performed at $868 \mathrm{MHz}$ frequency band by using the parameters in Table 1.

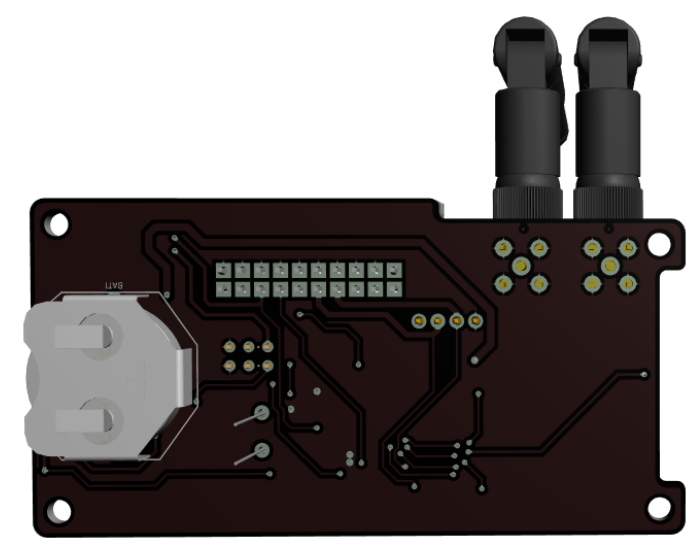

Figure 3. The back side view of designed LoRa weather station

The obtained coverage estimation map of RN2483 based weather station is shown by Figure 5. According to the built-in digital terrain model (DTM) of Aptica, it is possible to receive the meteorological reports sent from the weather station located between Burunoba and Akçaşehir through a gateway in Karaman city center. We also investigate the variation of the signal level on the propagation path between the centers of Karaman and Akçaşehir. As seen from Figure 6, the establishment of the LoRa connection is not feasible due to long distance and harsh topography of the terrain. It is obvious that the signal level fall under the receiver sensitivity due to the hills at the south-west of the Akçaşehir. But, thanks to the multiple gateway coexistence in LoRa network, it is still possible to create larger areas that are cover the entire apple orchards.

\section{Conclusions}

Recently, lots of LoRa deployments have been realized regarding the agricultural applications that are focus on remote monitoring of farming activities. Low cost, more flexibility and extended coverage are indispensable requirements of these applications to improve the efficiency of operations while maintaining the sustainable crop production. In this paper, a novel LoRa based weather station prototype design has been presented for building a private agricultural LoRa network. In addition, the coverage area of the planned LoRa network has been investigated by using Xirio Online radio planning tool. The apple orchards established around Akçaşehir region in Karaman province were selected as the target. It is clear that the completed conceptual design study will simplify the development process in near future.

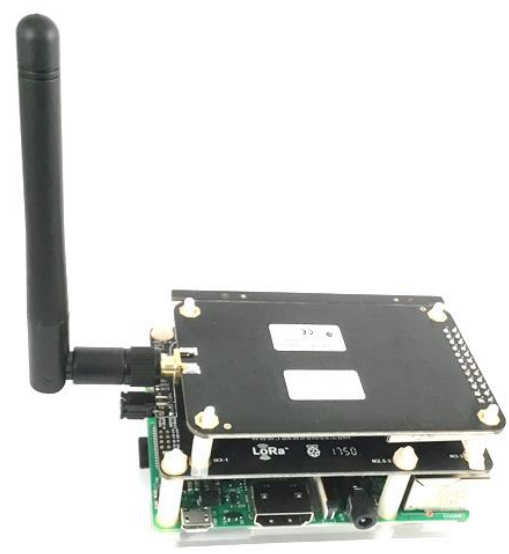

Figure 4. RAK831 based LoRa gateway with Raspberry Pi 
European Journal of Science and Technology

Table 1. Simulation parameters for coverage analysis

\begin{tabular}{|l|c|c|}
\hline Parameter & End Device & Gateway \\
\hline Antenna height & $1.5 \mathrm{~meter}$ & 3 meter \\
\hline Antenna gain & $2.15 \mathrm{dBi}$ & $2.15 \mathrm{dBi}$ \\
\hline Transmit power & $+14 \mathrm{dBm}$ & -- \\
\hline Receiver sensitivity & -- & $-142.5 \mathrm{dBm}$ \\
\hline
\end{tabular}

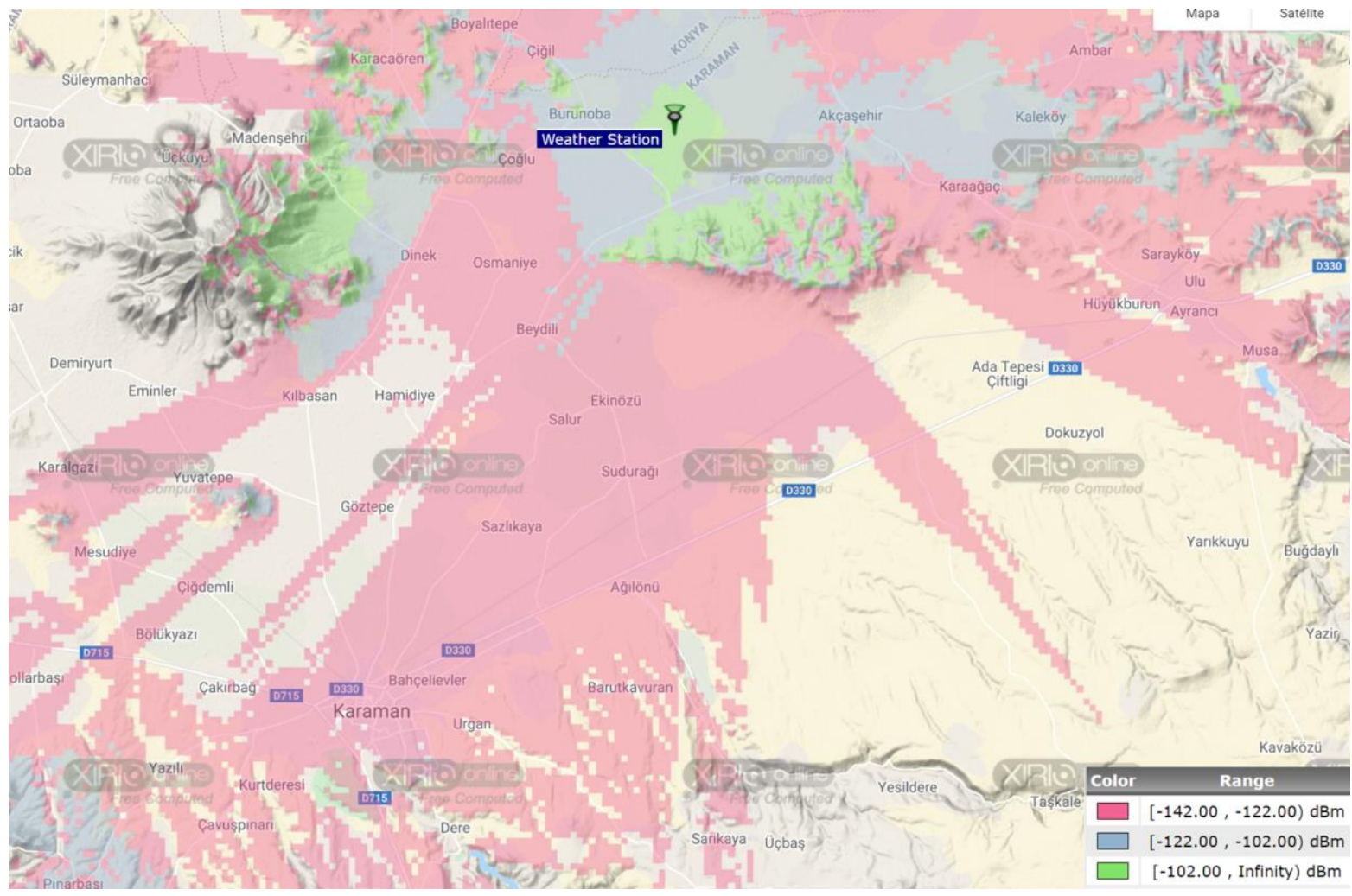

Figure 5. The coverage area of LoRa network with XIRIO tool
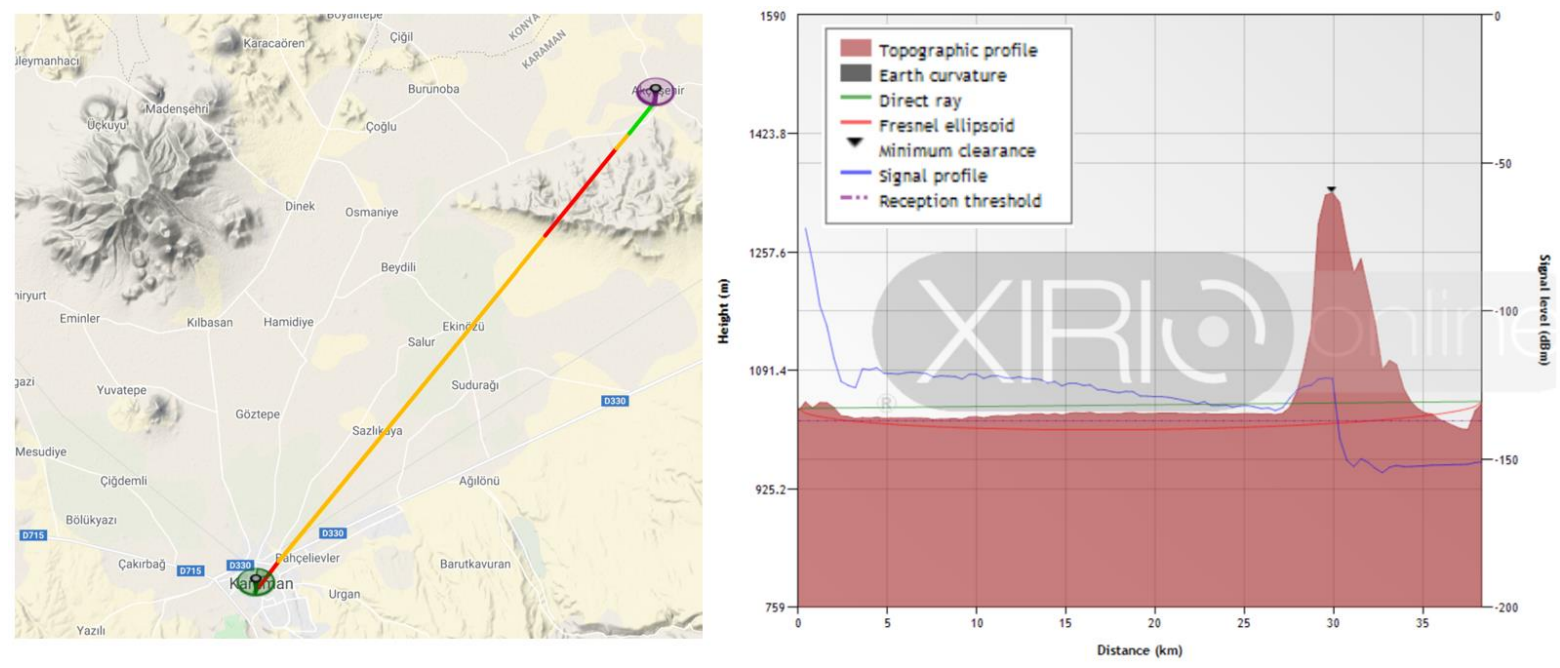

Figure 6. The signal level investigation with XIRIO tool 


\section{References}

Andrew, R. C., Malekian, R. \& Bogatinoska, D. C. (2018) IoT solutions for precision agriculture. 41st International Convention on Information and Communication Technology, Electronics and Microelectronics (MIPRO), 345-349, Opatija, Croatia.

Charania, I. \& Li, X. (2020) Smart farming: Agriculture's shift from a labor intensive to technology native industry. Internet of Things, 9(6), 1-20.

Elijah, O., Abd Rahman, T., Orikumhi, I., Leow, C. Y. \& Hindia, M. (2018) An Overview of Internet of Things (IoT) and Data Analytics in Agriculture: Benefits and Challenges. IEEE Internet of Things Journal, 5(5), 3758-3773.

EOS. (2021, January 26) Weather in Agriculture: Accuracy Promotes Success. https://eos.com/blog/weather-inagriculture

EPA. (2021) Climate Impacts on Agriculture and Food Supply. https://19january2017snapshot.epa.gov/climateimpacts/climate-impacts-agriculture-and-food-supply .html

Gyarmati, G. \& Mizik, T. (2020) The present and future of the precision agriculture. IEEE 15th International Conference of System of Systems Engineering (SoSE), 593-596, Budapest, Hungary.

Hatfield, J. L. \& Prueger, J. H. (2015) Temperature extremes: Effect on plant growth and development. Weather and Climate Extremes, 10, 4-10.

Lakhiar, I. A., Jianmin, G., Syed, T. N., Chandio, F. A., Buttar, N. A. \& Qureshi, W. A. (2018) Monitoring and Control Systems in Agriculture Using Intelligent Sensor Techniques: A Review of the Aeroponic System. Journal of Sensors, 2018, 1-18.

Li, C. \& Niu, B. (2020) Design of smart agriculture based on big data and Internet of things. International Journal of Distributed Sensor Networks, 16(5), 1-11.

Lohchab, V., Kumar, M., Suryan, G., Gautam, V. \& Das, R. K. (2018) A Review of IoT based Smart Farm Monitoring," Second International Conference on Inventive Communication and Computational Technologies (ICICCT), 1620-1625, Coimbatore, India.

Microchip Technology Inc. (2021) RN2483 Low-Power Long Range LoRa ${ }^{\circledR}$ Technology Transceiver Module Datasheet. http://ww1.microchip.com/downloads/en/DeviceDoc/RN24 83-Low-Power-Long-Range-LoRa-Technology-TransceiverModule-Data-Sheet-DS50002346D.pdf

Miorandi, D., Sicari, S., De Pellegrini, F. \& Chlamtac, I. (2012) Internet of things: Vision, applications and research challenges. Ad Hoc Networks, 10, 1497-1516.

RAKwireless. (2021) RAK831 WisLink LPWAN Concentrator. https://store.rakwireless.com/products/rak831-gatewaymodule? variant $=39942881083590$

Rubio, V. S. \& Más, F. R. (2020) From Smart Farming towards Agriculture 5.0: A Review on Crop Data Management. Agronomy, 10(2), 1-21.

TE Connectivity. (2017) MS8607-02BA01 PHT Combination Sensor Datasheet.

https://www.te.com/commerce/DocumentDelivery/DDEControll er?Action $=$ showdoc $\&$ DocId $=$ Data + Sheet $\%$ FMS860702BA01\%7FB3\%7Fpdf\%7FEnglish\%7FENG DS MS 8607 -02BA01 B3.pdf\%7FCAT-BLPS0018

The Food and Agriculture Organization (FAO) of the United Nations. (2011), The State of the World's Land and Water
Resources for Food and Agriculture: Managing Systems at Risk.

The Food and Agriculture Organization (FAO) of the United Nations. (2017), [2] Information and Communication Technology (ICT) in Agriculture: A Report to the G20 Agricultural Deputies.

Vining, K. C. (1990) Effects of weather on agricultural crops and livestock: an overview. International Journal of Environmental Studies, 36(1-2), 27-39. 